\title{
Online optical monitoring of polymer melting in a twin-screw extruder
}

\author{
Luciana Assumpção Bicalho ${ }^{1}$ | José António Covas ${ }^{2}$ | \\ Sebastião Vicente Canevarolo ${ }^{3}$ [우
}

\author{
${ }^{1}$ Programa de Pós-Graduação em Ciência \\ e Engenharia de Materiais-PPG-CEM, \\ Universidade Federal de São Carlos- \\ UFSCar, São Carlos, Brazil \\ ${ }^{2}$ Departamento de Engenharia de \\ Polímeros/IPC, Universidade do Minho, \\ Guimarães, Portugal \\ ${ }^{3}$ Departamento de Engenharia de \\ Materiais-DEMa, Universidade Federal \\ de São Carlos-UFSCar, São Carlos, \\ Brazil

\section{Correspondence} \\ Sebastião Vicente Canevarolo, \\ Departamento de Engenharia de \\ Materiais-DEMa, Universidade Federal \\ de São Carlos-UFSCar, Rod. Washington \\ Luis, km 235, 13565-905, Brazil. \\ Email: caneva@ufscar.br

\section{Funding information} \\ Conselho Nacional de Desenvolvimento \\ Científico e Tecnológico, Grant/Award \\ Number: 311790/2013-5; Coordenação de \\ Aperfeiçoamento de Pessoal de Nível \\ Superior, Grant/Award Numbers: Finance \\ Code 001, PDSE 88881.132167/2016-01, \\ PVE 30484/2013-01
}

\begin{abstract}
An experimental setup containing a sliding online optical device is used to monitor in real-time the melting process of a commercial polypropylene in a corotating intermeshing twin-screw extruder. Turbidity and birefringence are measured at several axial locations upstream and along the first restrictive zone of the screw, where melting develops. The experiments are performed using different set barrel temperatures, extruder feed rates, and screw speeds, to generate distinct flow histories and, accordingly, changes in the onset and rate of melting of the polymer. The local flow conditions are characterized in terms of residence time distribution and data equivalent to axial pressure profiles. Turbidity and birefringence are sensitive to changes in the operating conditions providing a coherent description of melting. The onset of melting seems to take place in partially filled conveying elements, and then melting develops quickly as the latter become fully filled, and is completed well before flow through the kneading block.
\end{abstract}

\section{KEYWOR D S}

birefringence, melting, online optical characterization, turbidity, twin-screw extruder

\section{1 | INTRODUCTION}

Extrusion compounding is a widely used technology for the production of complex polymer systems such as polymer blends, composites, and nanocomposites. Corotating fully intermeshing twin-screw extruders are commonly adopted for this purpose, given their modular construction (both the screws and barrel are assembled from a selection of available elements with different geometries), excellent distributive and dispersive mixing capability, good yield and the possibility to perform a variety of elementary processing steps ${ }^{[1,2]}$ For example, the manufacture of nanocomposites typically entails melting the polymer, feeding the filler(s), disperse the latter and homogenize spatially the ingredients, and pump the melt through the shaping die for subsequent pelletizing.

Melting is an important process stage, influencing the development of pressure and temperature along the screw axis, as well as accounting for at least $50 \%$ of the total energy consumption. ${ }^{[3]}$ Experimental investigations have also shown that immiscible polymer blends and nanocomposites experience major changes of morphology (and of chemical conversion in the case of reactive extrusion) upon melting. ${ }^{[4-6]}$ Melting is influenced by the local screw configuration (typically containing restrictive elements), by the physical form and properties of the 
feedstock and by the operating conditions (feeding rate, screw speed, barrel temperature).

Melting in corotating twin-screw extruders has been studied both experimentally and theoretically. Vergnes et $\mathrm{al}^{[7]}$ and Chen et $\mathrm{al}^{[8]}$ reviewed the experimental studies dedicated to unveiling the melting mechanisms in these machines. In general, it has been shown that the melting process is quicker and quite distinct from that in single screw extruders. Melting initiates close to the barrel wall, then pellets aggregate in clusters forming a solid-rich suspension that turns progressively into a liquid-rich suspension and finally into a melt. Much less has been reported on how melting and morphology development are related. ${ }^{[4,9]}$ Vergnes et $\mathrm{al}^{[7]}$ and Chen et $\mathrm{al}^{[8]}$ also reviewed the proposed theoretical melting models, which were often derived and/or adapted from the classic conductive melting models for single screw extrusion. ${ }^{[10]}$ In this respect, it is worth mentioning the contribution of Gogos et al, ${ }^{[2,11]}$ who demonstrated the important contributions to melting of plastic energy dissipation and of particle-to-particle frictional energy dissipation due to the repeated large compressive deformations taking place upon flow in fully filled kneading blocks.

Most of the current knowledge on melting in corotating twin-screw extruders has been obtained by performing screw-freezing experiments that were originally developed by Maddock ${ }^{[12]}$ in order to investigate the plasticating mechanism of single screw extruders. In these experiments, once steady-state extrusion is attained, the screw rotation is interrupted and the extruder is rapidly cooled, in order to freeze the polymer in the screws. These are then pulled out from the barrel, or disconnected from the screw shaft couplings, and removed from the machine if a clamshell barrel is being used. Transversal cross-sections of samples obtained from various locations along the screws are then examined in terms of the presence of solids and molten material. This methodology requires operation shut down, is time consuming and relatively complex. Also, Machado et $\mathrm{al}^{[13]}$ showed that in the case of polymer blends, melting, and coalescence of the dispersed phase continue to develop during the time elapsing between shutdown and the removal of the screws from the machine.

Studies of melting during operation of the extruder have been done using a special barrel containing a heatresistant glass window installed on a side wall. ${ }^{[14]}$ Chen et $\mathrm{al}^{[8,15]}$ used a sliding barrel (containing a glass window less than 1D long) technique combined with a high-speed video to visualize online the melting of a polystyrene/ polypropylene (PS/PP) blend.

Obtaining real-time quantitative data on melting would greatly simplify experiments, and contribute to a better insight into the effects on melting of operating conditions, screw geometry, and material formulations. Optical techniques are quite attractive for this purpose since they have fast response times and do not disturb the environment being analyzed. ${ }^{[16-31]}$ For example, turbidity can be measured by following changes in transmitted light intensity, thus quantifying the level of light scattering $^{[17,25,30]}$ and the deformation of the dispersed particle shape during flow in polymer mixtures. ${ }^{[21,29]}$ The latter is mainly produced by the solid-molten interfaces present in the medium, which decrease as melting develops. Another important optical property is birefringence, which provides an indication of the level of molecular chain orientation in the molten portion of the polymer flow. ${ }^{[18,22,26-28]}$ Low angle laser light scattering, in-line (LALLS) ${ }^{[20]}$ can also provide an indication of the level of molecular orientation induced during polymer flow or in the solid state. Residence time distribution (RTD) curves can be obtained by introducing a tracer in the polymer flow and following its concentration at the selected location. ${ }^{[16,19,23,24,31]}$

This work presents a new experimental setup consisting of a modified barrel segment of a commercial corotating intermeshing twin-screw extruder containing optical devices, as well as the procedure to quantify online the level of polymer melting at different axial locations. As melting develops, the content of solid-molten polymer interfaces decreases, reducing the light scattering as transmitted light intensity, that is, turbidity declines. By cross polarizing the light path birefringence coming from the orientation of polymer chains in the molten polymer phase, complementary information on the progressive increase in the amount of molten material can also be obtained. From this set of online data, the axial melting profile of the polymer along the first kneading zone of the screws can be deduced.

\section{2 | EXPERIMENTAL}

\section{1 | Materials}

A polypropylene homopolymer (ELTEXP HV001PF, produced by INEOS Olefins \& Polymers Europe) with density of $0.905 \mathrm{~g} / \mathrm{cm}^{3}$ and MFI $=10 \mathrm{~g} / 10$ minutes $(2.16 \mathrm{~kg}$, $190^{\circ} \mathrm{C}$ ) was used in the experiments. The polymer was supplied in powder form, in order to avoid eventual clogging the multislit die, as explained below.

\section{2 | Twin-screw extruder setup}

The experiments were performed in a modular corotating intermeshing twin-screw extruder Collin ZK 25P (screw 

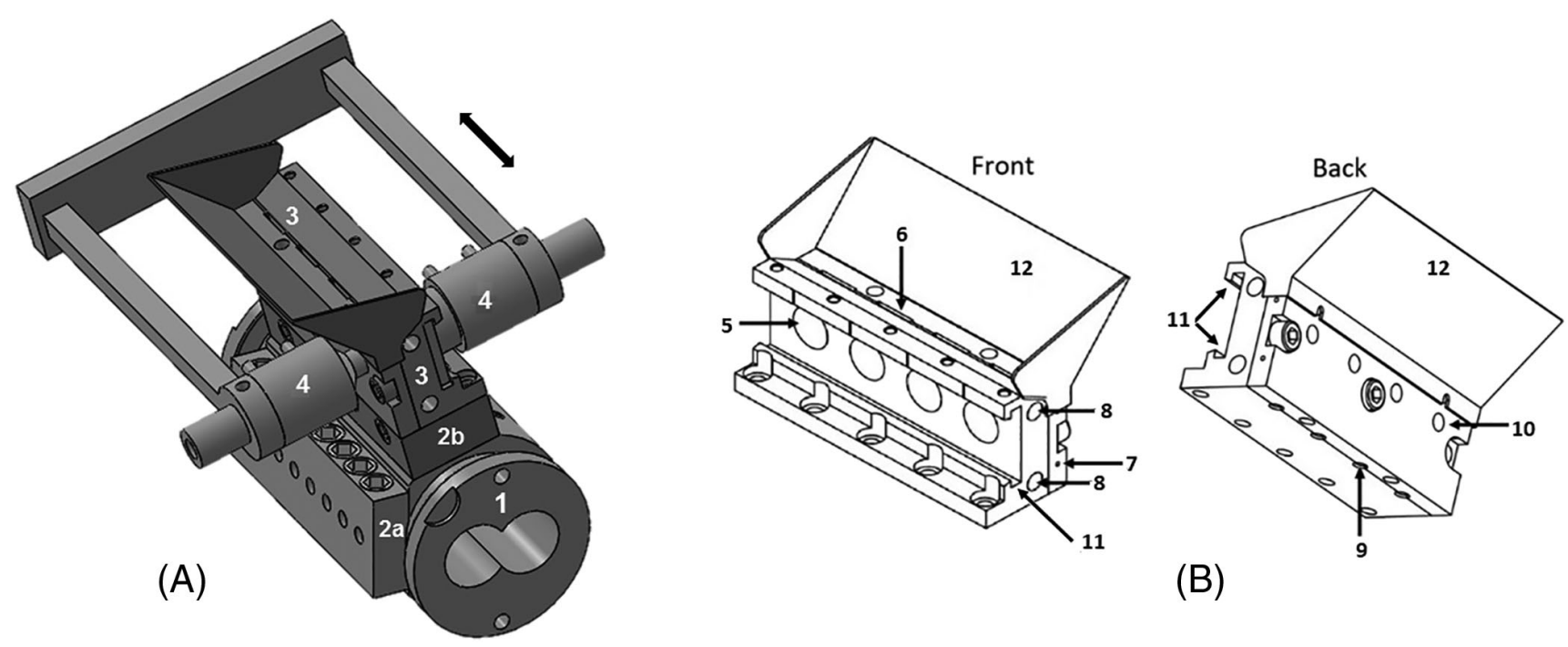

(B)

F I G U RE 1 A, Experimental setup. Modified barrel module of a corotating twin-screw extruder (1) containing two rows of sampling devices operated by rotating valves (2a, 2b); multislit die (3) coupled to row $2 \mathrm{~b}$ and sliding optical detection system (4). B, multislit die with four slits, each containing a pair of transparent optical windows; (5) front optical glass window; (6) slit exit; (7) hole to fix the thermocouple; (8) holes to accommodate cartridge heaters; (9) slit entrance; (10) rear optical glass window; (11) groove for positioning the sliding optical detector; (12) cover to prevent the melt from spilling

diameter of $25 \mathrm{~mm}$ and $\mathrm{L} / \mathrm{D}=42$ ) and using a K-Tron gravimetric feeder. The original second barrel module of the extruder (adjacent to the module containing the feed opening) was replaced by another with a modified design. Figure 1A shows the entire experimental setup, which includes the modified barrel module (1) containing two axial rows of sample collecting devices at the side (2a) and top (2b) of the barrel. They follow the design previously developed by the authors to study the progress of physicochemical phenomena along the axis of the extruder. ${ }^{[13]}$ In this work, only the four collecting devices at the top row (2b) were used. Each contains a rotating on-off valve, which when rotated $90^{\circ}$ via a Hex key, enables the material to flow out of the extruder, passing along a circular side channel linking the inner and outer extruder barrel walls, and then flowing through one of the slits of the multislit die (3). Rotating the valve another $90^{\circ}$ cuts-off flow. The multislit die and a sliding optical detection system (4) were specifically designed for this application. As shown in Figure 1B, the multislit die contains four channels, set $25 \mathrm{~mm}$ apart. Each slit is $30 \mathrm{~mm}$ long, $15 \mathrm{~mm}$ wide, and $1.5 \mathrm{~mm}$ thick. The inlet of each slit is a circular channel with a diameter of $5 \mathrm{~mm}$ (9), matching one of the channels linking the inner and outer barrel walls and containing on-off valves. A taper gradually converts the inlet circular channel into the slit. Each slit contains a pair of directly opposed transparent circular windows $(5,10)$, with a diameter of $10 \mathrm{~mm}$. The temperature of the multislit die was kept equal to that of the extruder barrel by two PID controlled cartridge heaters (8). The flow that comes out of the slit (6) is collected on a cover (12).

Figure 2 presents the layout of the initial part of the extruder, between the material feeding port and downstream of the first restrictive zone of the screw. As identified in the figure, the restriction comprises two kneading blocks, each $15 \mathrm{~mm}$ long and containing five individual disks $3 \mathrm{~mm}$ thick, staggered positively at $45^{\circ}$, followed by two left-handed (LH) conveying elements, each $15 \mathrm{~mm}$ long. This configuration intended to cause flow in several fully filled screw channels upstream of the LH elements, thus facilitating sample collection. Moreover, it was anticipated that polymer melting should initiate in the last turns of the positive conveying elements upstream of the kneading block, and eventually develop along the latter. The figure also outlines the locations for sample collection in terms of the L/D (axial length/screw diameter) ratio, that is, where upon opening the on-off valves the material will flow through the collecting devices and through the multislit dies containing the optical windows for measuring the transmitted light intensity. Given the geometry of the screws and of the modified barrel, the locations were the following: $\mathrm{L} / \mathrm{D}=13$ and $\mathrm{L} / \mathrm{D}=14$ are positioned along the conveying section, 50 and $25 \mathrm{~mm}$ upstream from the kneading block, respectively; L/D $=15$ is situated between the end of the conveying element and the start of the kneading block; $\mathrm{L} / \mathrm{D}=16$ is set between the end of the kneading block and the start of the left handed element.

Although sample collection may perturb the flow characteristics in the extruder downstream of the location 


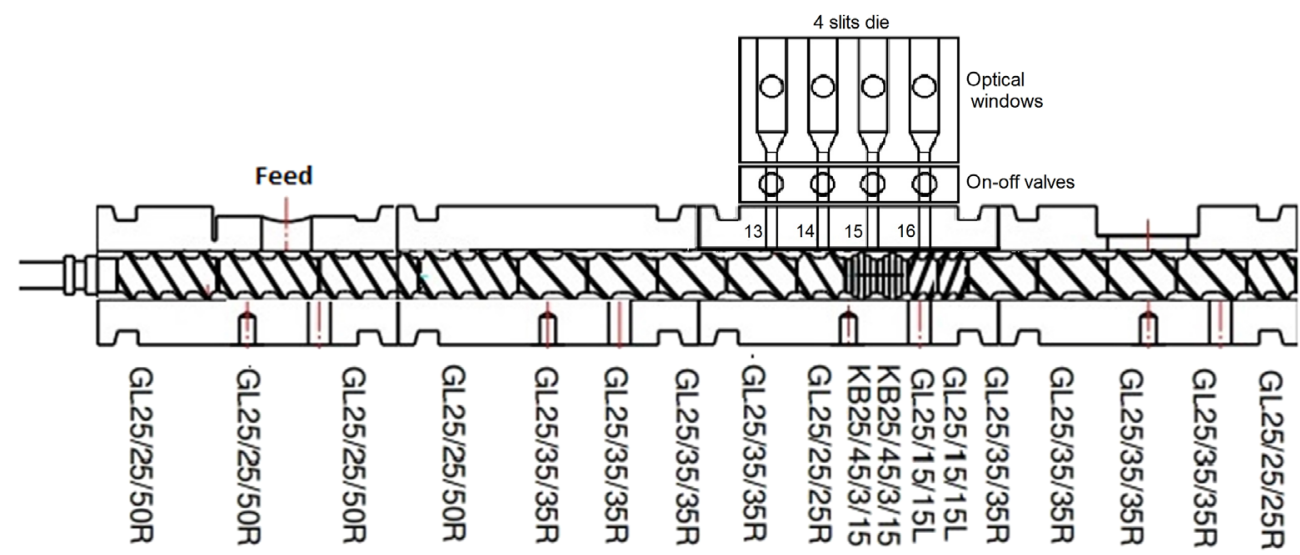

FI G URE 2 Layout of the sector of the extruder where the experiments were performed. The material flowing in the extruder was diverted from the screw channel into the multislit die for optical quantification between locations $\mathrm{L} / \mathrm{D}=13-16$, by rotation of the on-off vales [Color figure can be viewed at wileyonlinelibrary.com]

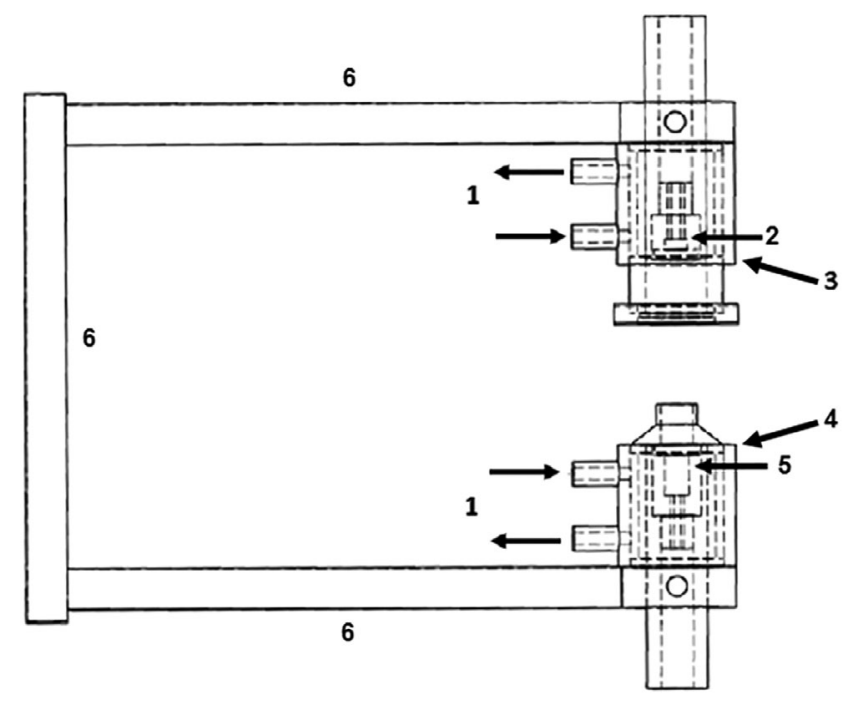

FI G URE 3 Online optical detector developed to measure the transmitted light intensity of the material stream through the multisit die. (1) Water cooling system, (2) two photodetectors (LDR), (3) analyzer filter, covering only one LDR, (4) polarizer filter, (5) white light emitter diode (LED), (6) C-shaped rigid frame. The assembly can slide along the width of the multislit die while maintaining the light beam aligned

being analyzed, the advantages of the method largely outweigh its limitations. Also, since both residence time and shear rate in the side channel and slit are quite low, the continuation of melting inside them during sample collection should be negligible. Contrariwise, Maddock experiments usually entail letting the material in the screws being subjected to high-temperatures for a few minutes. $^{[12]}$

\subsection{Online optical detector system}

The transmitted light intensity across the stream of material diverted from the extruder was measured by the optical detector shown in Figure 3. The device contains two opposed and aligned water-cooled cylinders secured together by a $\mathrm{C}$-shaped rigid frame that can slide along the width of the multislit die in order to become appropriately aligned with each pair of optical windows existing in each slit. The light beam emitted from the lower cylinder passes through the flowing polymer and reaches the second upper cylinder holding two photodetectors.

The lower cylinder holds the light source, normally a white bright light emitter diode (LED), but that can be replaced by another with different wavelength (color) if needed. A polarizing filter is added in front of the light source for the birefringence measurements, but it does not affect the turbidity measurement. The upper cylinder holds a pair of photodetectors (LDRs). The first measures the transmitted light intensity, which quantifies the turbidity data. The second is covered by a polarizing filter (analyzer), set crossed to the first polarizing filter, and quantifies the cross-polarized transmitted light intensity, which accesses the flow birefringence data. The LDRs and the LED are independently adjustable to ensure different detection levels, which are necessary given the broad range of light intensities that are to be expected. Indeed, different operating conditions and axial positions may involve the flow in the slits of solids, of a solids-liquid suspension, or of a melt, depending on the position and local degree of melting.

The signals from the two LDRs measuring synchronously turbidity and birefringence are collected at a frequency of $0.1 \mathrm{MHz}$, converted into digital signals by means of an analogic-digital interface (USB data acquisition NI-DAQ 6812), transmitted to a personal computer running the software developed in the LabView $8.6 \mathrm{NI}$ platform (from National Instruments), which averages (compresses) the data to present it at $10 \mathrm{~Hz}$, makes the real-time calculations, screen presentation, and data saving.

The optical system was validated by comparing the response of the two LDRs to a set of fixed luminous 
intensities emitted by the LED to that of a standard International Light Technologies ILT 1400 radiometer/photometer. ${ }^{[32]}$ Since the two sets of data (not shown) were nearly overlapped, the detection system was considered as suitable for making quantitative measurements.

\section{4 | Turbidity}

Turbidity can be used to monitor polymer melting in real-time by relying on the light scattering produced in the solid-molten interface of the suspended solid polymer particles present in the stream flowing from inside the extruder through the collecting devices and slits. Indeed, the small difference in refractive index between molten and solid PP is enough to produce light scattering at the solid-liquid interface. As melting progresses, the solidmolten interface content reduces and so does the light scattering level, increasing the transmitted light intensity, that is, reducing turbidity. When melting is complete, a maximum transmitted light intensity, the so-called baseline, is reached.

The transmitted light intensity measured by the optical detector can be normalized $\left(V_{N}\right)$ to a dimensionless value varying between zero (for fully molten polymer flow) and one (maximum light scattering, no light gets through the polymer flow) ${ }^{[23]}$ :

$$
V_{N}=\frac{V-V_{0}}{V_{s}-V_{0}}
$$

where $V$ is the measured polymer flow response voltage, $V_{S}$ is the saturation detector response when the light source is switched off, and $V_{0}$ is the fully molten sample response or baseline voltage.

Many optical effects may contribute to nonlinearity between turbidity and dispersed phase volume fraction. For a fixed pair matrix/dispersed phase, the most important deleterious effects are: (a) matrix and dispersed phase having near matching refractive indices, (b) particles diameter being outside the best scattering range, (c) too high number of scattering particles, and (d) multiple light scattering. To reduce such effects, one should operate with sufficiently low volume fraction of the scattering dispersed phase to keep turbidity values lower than 0.1 (10\% of the full range scale). Changes in the dispersed phase morphology of diluted polymer mixtures can be followed offline measuring turbidity. For example, a setup with a photometer inserted in a polarized light optical microscope and a shearing system can deform the polymer mixture under controlled conditions, changing the dispersed droplets cross section and affecting turbidity.

\section{5 | Flow birefringence}

The molecular chain orientation during polymer melt flow produces flow birefringence. The freshly molten material is relatively cold (and, consequently, has a high viscosity), high local thermomechanical stresses develop in the restrictive zones, thus resulting in significant chain orientation, and so in flow birefringence. The molecular orientation happens solely in the molten phase of the flowing stream, hence contributing to estimate its molten polymer content.

The cross-polarized transmitted light intensity acquired by the optical detector can also be normalized $\left(V_{N}^{c}\right)$ as a dimensionless value varying between zero and one $^{[26-28]}$ :

$$
V_{N}^{c}=\frac{V-V_{c}}{V_{p}-V_{c}}
$$

where $V$ is the measured sample response voltage, $V_{c}$ is the cross-polarized response voltage when the polar filters are set as crossed (minimum value) and $V_{p}$ is the voltage response when the filters are set as parallel (maximum value).

The orientation of polymer chains aligns their polar groups in the flow direction, creating a difference between the orthogonal refractive indices (along and across the flow), producing an optical path difference (OPD) that is related to the normalized (dimensionless) cross-polarized transmitted light intensity by, ${ }^{[28]}$

$$
O P D=\frac{550}{\pi} \times \sin ^{-1} \sqrt{V_{N}^{c}}
$$

when using white light illumination having an average wavelength of $550 \mathrm{~nm}$. The birefringence is the normalization of the OPD by the light optical path, measured in nanometers, that is, the sample (slit die) thickness $t$, which is fixed at $1500 \mathrm{~nm}$ :

$$
\text { Birefringence }=\frac{\mathrm{OPD}}{t}=\frac{\mathrm{OPD}}{1500}
$$

Polypropylene is a nonpolar polymer showing positive low values of flow birefringence, in the range of 0.5 to $1 \times 10^{-4}$.

\section{6 | Residence time distribution}

RTD curves were obtained by inserting a tracer pulse at the entrance of the system and measuring its concentration with time at the selected location downstream. In the present study, a $0.055 \mathrm{~g}$ pulse of general purpose polystyrene (Polystyrol 148 HQ from BASF), with a density of $1.049 \mathrm{~g} / \mathrm{cm}$ and $\mathrm{MFI}=6 \mathrm{~g} /$ minute $\left(5.0 \mathrm{~kg}, 200^{\circ} \mathrm{C}\right)$, 
corresponding to a concentration lower than $0.1 \% \mathrm{wt} / \mathrm{wt}$ relative to the PP matrix, was added to the feed opening of the extruder and its concentration was monitored upon flow through one of the lateral slits, by means of the optical detector. Separate experiments were performed for each slit of the multislit die. The PS tracer disperses as micrometric particles (or droplets) in the matrix that scatters light and is detected by the optical sensor as turbidity. Measurements were made at $185^{\circ} \mathrm{C}$ and above, which are high enough to ensure that the PP was completely molten, thus suppressing its solid-molten interface scattering effect.

\section{7 | Operating conditions}

Extrusion experiments were performed using barrel temperatures ranging from $167^{\circ} \mathrm{C}$ (just above the $\mathrm{PP}$ theoretical melting temperature of $165^{\circ} \mathrm{C}$ ) to $180^{\circ} \mathrm{C}$, extruder feed rates between 3 and $15 \mathrm{~kg} / \mathrm{h}$ and screw speeds varying from 30 to $500 \mathrm{rpm}$. In each case, upon reaching extrusion steady state, turbidity and birefringence measurements were made using the optical detector positioned on the relevant slit of the multislit die. The rotating valve of the collecting device was opened and maintained in the on-position while a stream of material emerged from inside the extruder, flowed through the valve channel till the slit where the optical measurements were made. After a measurement the valve was closed, the optical detector was slid to the next slit transparent window and the procedure was repeated for the remaining slits, whenever there was material streaming out of the extruder. At locations where the screw channel works partially filled, the material does not flow continuously through the collecting devices. RTD curves were also obtained at the same locations and processing conditions.

Information directly related to the local filling of the screws and to the axial pressure profile developing along the screws was obtained by measuring the flow rate at each of the slits of the multislit die while keeping the barrel at $210^{\circ} \mathrm{C}$, and for a feeding rate of $3 \mathrm{~kg} / \mathrm{h}$ and screw speeds varying from 30 to $500 \mathrm{rpm}$. In fact, upon opening the on-off valve of each sample collecting device, a pressure flow of the material in the screw develops toward the outlet of the adjoining slit when the screws are fully filled and the material is under pressure. That flow rate is directly proportional to the local pressure in the screw channels, and since the geometry of all the sampling devices and attached slits is identical, differences in the output of the various slits imply differences in the local pressures.

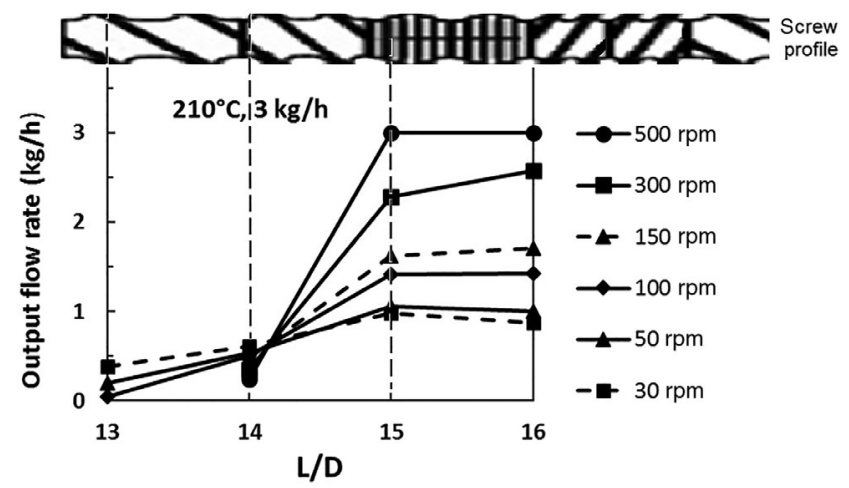

F I G URE 4 Flow rate through the slits along the modified barrel as a function of screw speed (barrel temperature set at $210^{\circ} \mathrm{C}$, extruder feed rate of $3 \mathrm{~kg} / \mathrm{h}$ ). The slit flow rate is an indication of the local pressure in the screw channel

\section{3 | RESULTS AND DISCUSSION}

\section{1 | Flow in the first restrictive zone of the screw}

Figure 4 shows the change in slit flow rate along the sector of the screw under analysis (ie, between $\mathrm{L} / \mathrm{D}=13$ and $L / D=16)$, at constant extruder feed rate $(3 \mathrm{~kg} / \mathrm{h})$ and barrel temperature $\left(210^{\circ} \mathrm{C}\right)$ for screw speeds ranging from 30 to $500 \mathrm{rpm}$. In each slit, a pressure flow develops, due to the difference between the pressure in the screw channel and the pressure at the exit of the slit, which is (approximately) nil. Therefore, each slit flow rate is directly related to the local hydrostatic pressure in the screw channel, meaning that Figure 4 can be interpreted as representing axial pressure profiles. As shown in the figure (and also in Figure 2), while $\mathrm{L} / \mathrm{D}=13$ and $\mathrm{L} / \mathrm{D}=14$ are situated along the conveying zone upstream of the restrictive zone, $\mathrm{L} / \mathrm{D}=15$ and $\mathrm{L} / \mathrm{D}=16$ correspond to the beginning of the kneading block, and beginning of the first LH element, respectively, which are flow restrictive zones. For all screw speeds, the slit flow rate (and so the pressure) increases progressively up to the start of the kneading block, keeping almost constant along it, in order to overcome the flow resistance downstream imposed by the LH element. Upon traversing the LH element, the pressure should decrease gradually and become nil at the beginning of the next conveying element, which should work partially filled. ${ }^{[1]}$ The higher the screw speed, the higher the maximum pressure developed (and thus the thermomechanical stresses), as the flow resistance created by the $\mathrm{LH}$ elements downstream also increases. Also, the higher the screw speed the higher the slope of the pressure increase, which influences the number of fully filled channels in the 

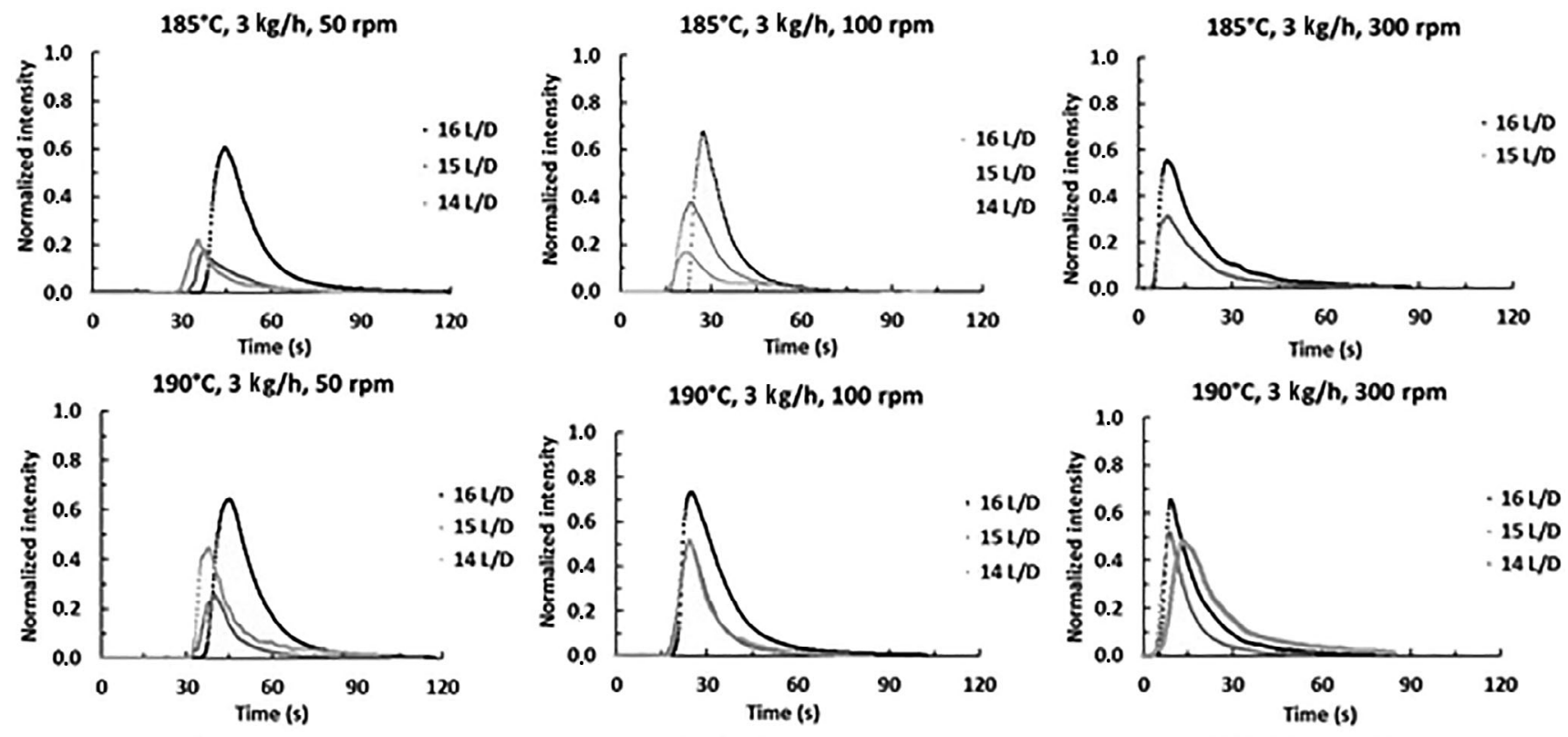

$190^{\circ} \mathrm{C}, 3 \mathrm{~kg} / \mathrm{h}, 100 \mathrm{rpm}$
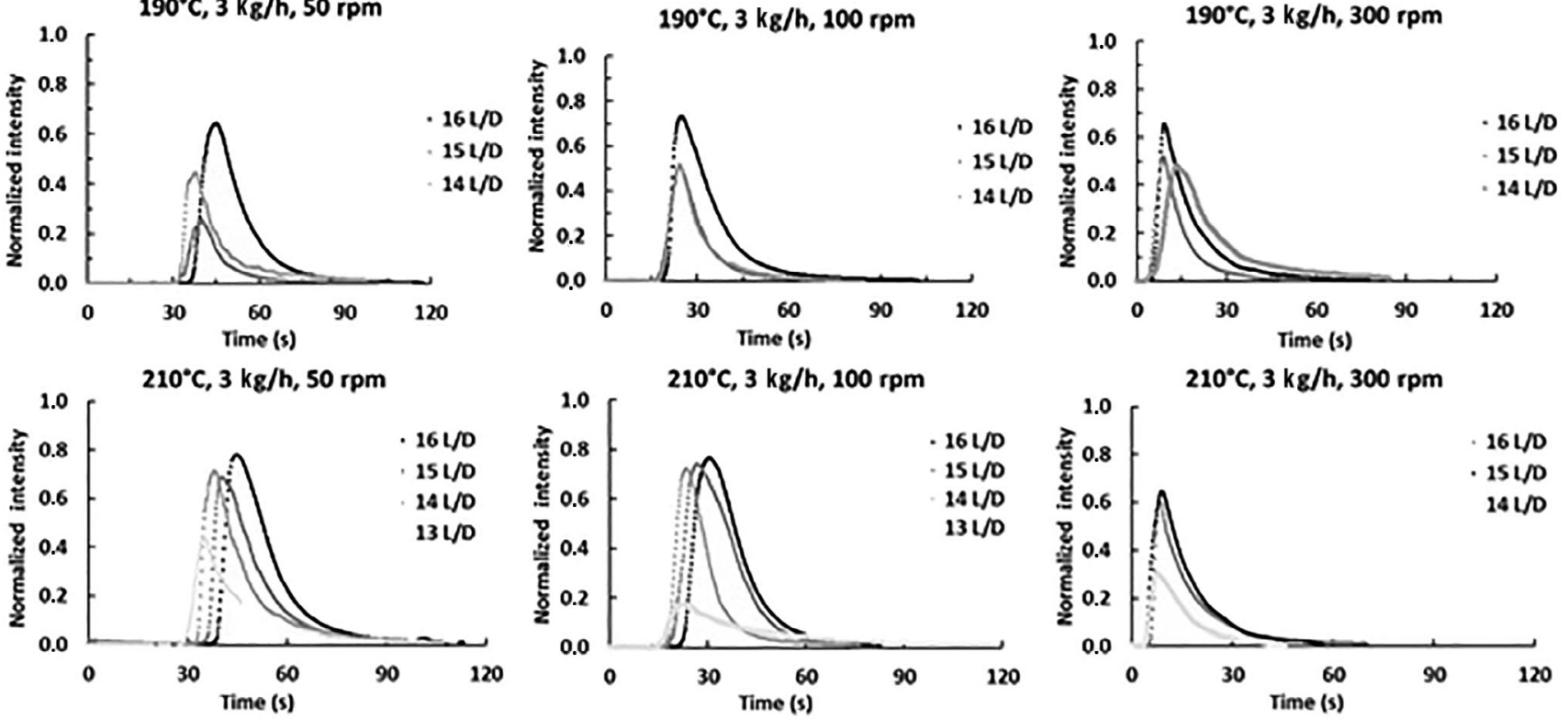

F I G U RE 5 Residence time distribution curves measured at the various sampling locations (L/D = 13 to L/D = 16), at constant extruder feed rate $(3 \mathrm{~kg} / \mathrm{h})$ and varying barrel temperatures $\left(185,190\right.$, and $\left.210^{\circ} \mathrm{C}\right)$ and screw speeds $(50,100$, and $300 \mathrm{rpm})$. Pulse of PS tracer with constant weight

conveying section upstream. Indeed, while at the lower screw speed range (between 30 and $100 \mathrm{rpm}$ ) the screw channel seems to be already fully filled at $L / D=13$, measurements of output flow rate could only be made for $\mathrm{L} / \mathrm{D}=14$ onwards for screw speeds equal to or above $150 \mathrm{rpm}$.

Figure 5 shows the RTD curves, measured as normalized transmitted light intensity, which is proportional to the concentration of the PS particles used as tracer, against time. They were measured at the various sampling locations, when operating with an extruder feed rate of $3 \mathrm{~kg} / \mathrm{h}$, for several screw speeds $(50,100$, and $300 \mathrm{rpm})$ and barrel temperatures $\left(185^{\circ} \mathrm{C}, 190^{\circ} \mathrm{C}\right.$, and $\left.210^{\circ} \mathrm{C}\right)$. Due to the high rate of data acquisition and compression, the curves are quite smooth and exhibit the expected pulse-like shape. ${ }^{[28,30]}$ It is evident from the figure that the operating conditions and sampling location influence the normalized transmitted light intensity, and the initial $\left(t_{i}\right)$ and average $\left(t_{m}\right)$ residence times. $t_{i}$ and $t_{f}$ are the initial and final residence times, that is, the time at which the first and the last tracer particles are detected respectively; and $t_{m}$ is the average residence time, which can be calculated as:

$$
t_{m}=\frac{\int_{0}^{\infty} t c d t}{\int_{0}^{\infty} c d t}=\frac{\sum_{0}^{\infty} t c \Delta t}{\sum_{0}^{\infty} c \Delta t}=\frac{\sum_{t_{i}}^{t_{f}} t V_{N} \Delta t}{\sum_{t_{i}}^{t_{f}} V_{N} \Delta t}
$$

For an easier comparison of the features of the RTD curves, Figure 6 shows the curves measured at L/D $=16$ and constant barrel temperature of $185^{\circ} \mathrm{C}$ for different screw speeds and input feed rates. As anticipated, higher screw speeds (at constant extruder feed rate) and higher extruder feed rates (at constant screw speed) shift the curves horizontally toward shorter times. Within the range of operating conditions tested, the initial residence time for the material to progress from the feed opening of the extruder until flowing in the lateral slit at $\mathrm{L} / \mathrm{D}=16 \mathrm{can}$ fluctuate between approximately 5 seconds $(3 \mathrm{~kg} / \mathrm{h}$, $500 \mathrm{rpm}$ ) and 38 seconds $(3 \mathrm{~kg} / \mathrm{h}, 50 \mathrm{rpm})$. Conversely, barrel temperature has little effect on RTD. 

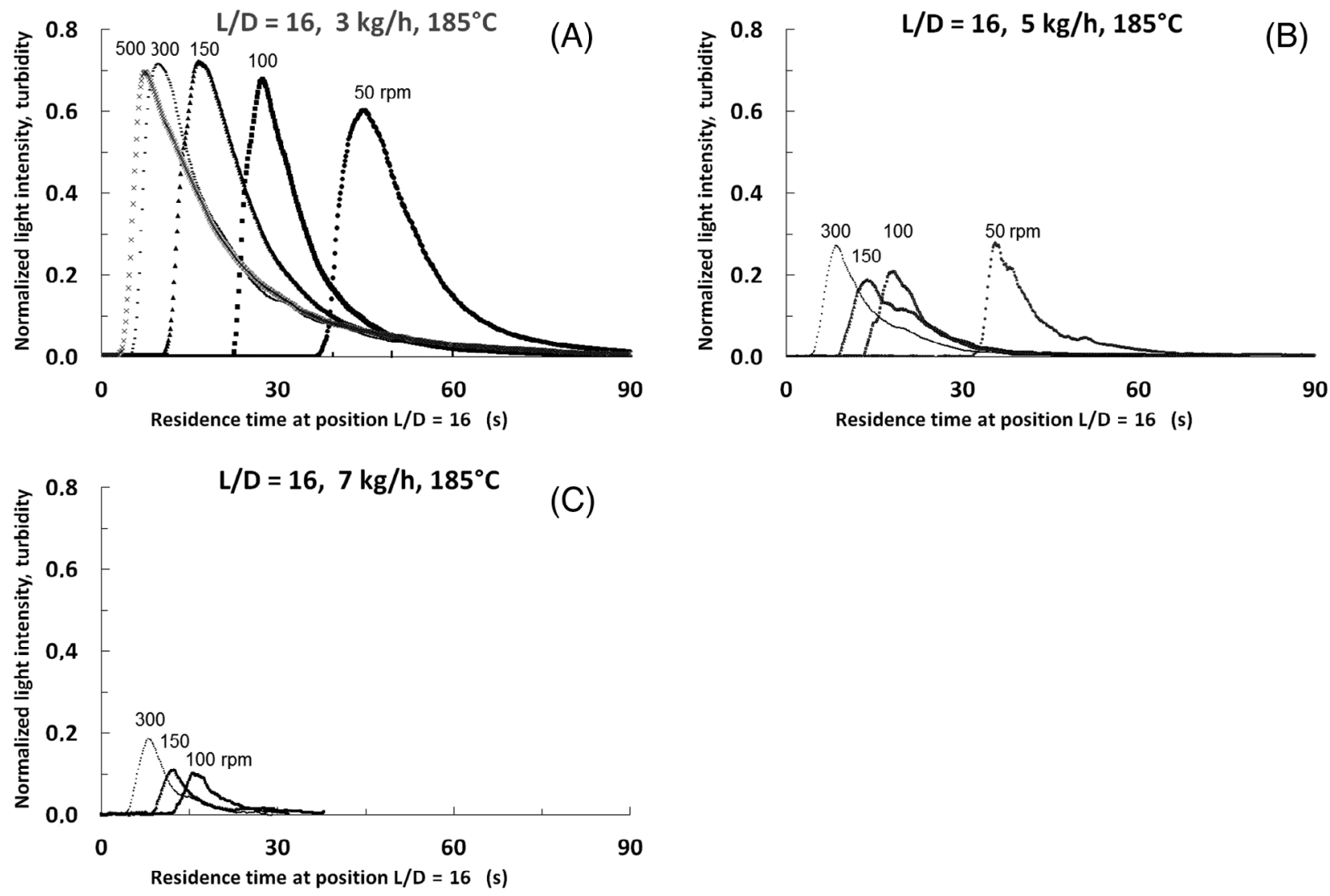

F I G U RE 6 Residence time distribution curves measured at $\mathrm{L} / \mathrm{D}=16$, with the barrel temperature set to $185^{\circ} \mathrm{C}$ and various screw speeds (50-500 rpm), for an extruder feed rate of: A, $3 \mathrm{~kg} / \mathrm{h} ; \mathrm{B}, 5 \mathrm{~kg} / \mathrm{h}$; and C, $7 \mathrm{~kg} / \mathrm{h}$. Pulse of PS tracer with constant weight

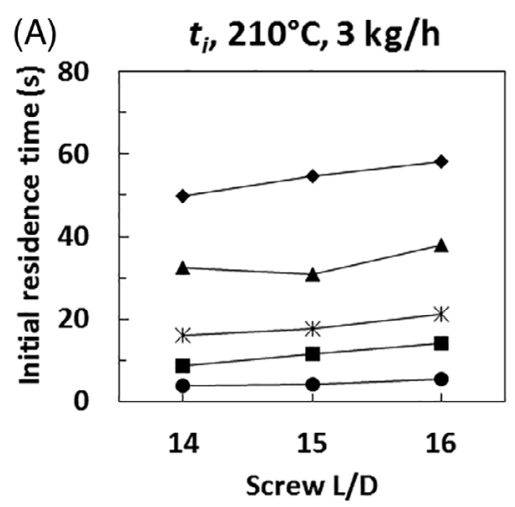

(B)

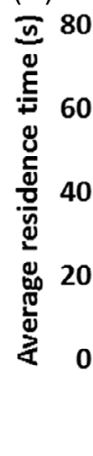

$t_{m}, 210^{\circ} \mathrm{C}, 3 \mathrm{~kg} / \mathrm{h}$

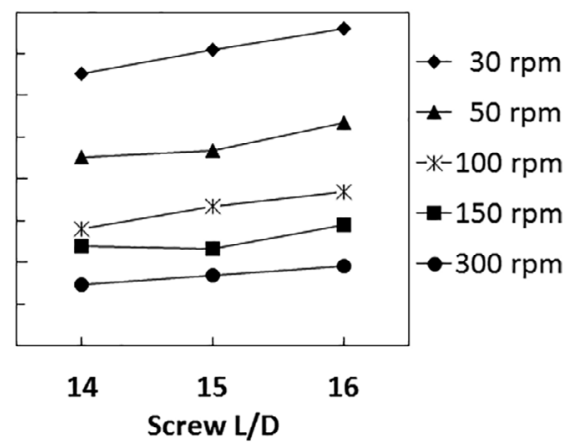

FIG U RE 7 Effect of screw speed on the A, initial $\left(t_{i}\right)$ and B, average $\left(t_{m}\right)$ residence times along each segment of the screw under study (barrel temperature set to $210^{\circ} \mathrm{C}$, extruder feed rate of $3 \mathrm{~kg} / \mathrm{h}$ )
The turbidity (or, equivalently, normalized light intensity) is directly dependent on the number of scattering particles and on their scattering cross section and is inversely proportional to the average particle size. The number of scattering particles depends on the tracer concentration (weight of PS pulse) and on its level of dispersion in the PP matrix. In turn, dispersion should result from the intensity of shearing experienced by the stream of material. Thus, as expected, turbidity reduces with increasing extruder feed rate $(3-7 \mathrm{~kg} / \mathrm{h})$. Given the constant amount of tracer used in the experiments, its content in the system decreases with increasing extruder feed rate, which explains the reduced areas below the corresponding RTD curves.

Figure 7 shows the effect of screw speed on the RTD, in terms of the initial $\left(t_{i}\right)$ and average $\left(t_{m}\right)$ residence times, at constant barrel temperature and extruder feed rate $\left(210^{\circ} \mathrm{C}, 3 \mathrm{~kg} / \mathrm{h}\right)$. As expected, the initial and average residence times decrease with increasing screw speed and increase along the screw axis. The decrease of $t_{i}$ and $t_{m}$ is 


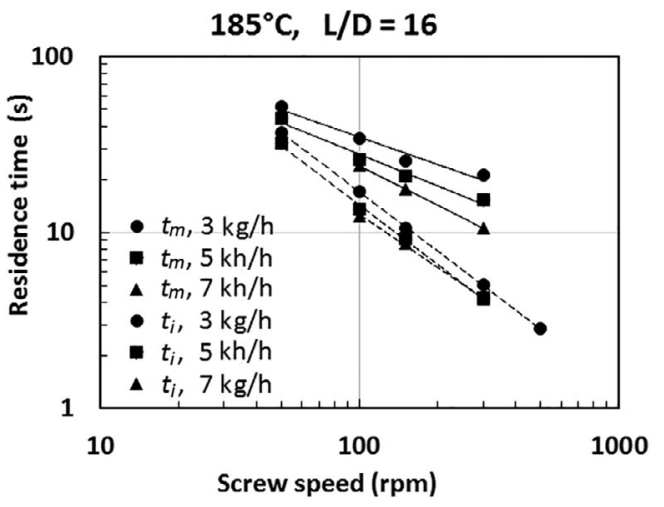

FI G URE 8 Effect of extruder feed rate and screw speed on the initial $\left(t_{i}\right)$ and average $\left(t_{m}\right)$ residence times at $\mathrm{L} / \mathrm{D}=16$ and extruder temperature set to $185^{\circ} \mathrm{C}$

more significant when the screw speed increases from 30 to $100 \mathrm{rpm}$, which is consistent with published data $^{[1,28,30]}$ and is most probably due to the fact that less screw channels work fully filled, as shown in Figure 4. Also, at the higher screw speed range, the residence times tend to rise less between $\mathrm{L} / \mathrm{D}=14$ and $\mathrm{L} / \mathrm{D}=15$. Again as shown in Figure 4, at these speeds the channels in the conveying zone upstream of the kneading block work partially filled until $\mathrm{L} / \mathrm{D}=15$. Figure 8 shows the effects of extruder feed rate and screw speed on the initial $\left(t_{i}\right)$ and average $\left(t_{m}\right)$ residence times, at $\mathrm{L} / \mathrm{D}=16$ (constant barrel temperature of $185^{\circ} \mathrm{C}$ ). As anticipated, an increase in the extruder feed rate yields lower residence times. Typically, all other parameters being constant, increasing the extruder feed rate from 3 to $7 \mathrm{~kg} / \mathrm{h}$ will cause a decrease of $t_{m}$ of $30 \%$ at $100 \mathrm{rpm}$ and $50 \%$ at $300 \mathrm{rpm}$.

\section{2 | Online monitoring of polymer melting}

The data on the slit flow rate (as discussed, this flow rate is proportional to the local pressure drop) of the modified barrel and the RTD measurements indicated that the operating conditions selected for the extrusion experiments generated distinct flow histories along the screw segment being studied. In principle, these should influence polymer melting both in terms of onset and rate, which should be detected online by both optical techniques, turbidity and birefringence.

Online turbidity measurements were used to follow melting of PP. As melting develops, the surface area of the solid-liquid interfaces decreases, reducing its light scattering intensity, and likewise the turbidity, which is optically detected as an increase in the transmitted light intensity. Therefore, when only solids are present in the screw channel, turbidity will be at its highest (theoretically one, the value preset with the light source off, during the initial parametrization of the detector). Upon melting, this value will progressively decrease to zero (this value preset with the slit-die channel filled with fully molten PP). Feeding the extruder with PP powder did not cause slit blockage in any of the experiments, even when running at a temperature as low as $167^{\circ} \mathrm{C}$. Also, no particle agglomeration could be detected while the polymer flow crosses the detector.

Figure 9 shows the effect of screw speed on turbidity at the different sampling locations, for three barrel temperatures $\left(167^{\circ} \mathrm{C}, 170^{\circ} \mathrm{C}\right.$, and $175^{\circ} \mathrm{C}$, Figure $9 \mathrm{~A}, \mathrm{~B}$, and $\mathrm{C}$, respectively) for a fixed extruder feed rate of $3 \mathrm{~kg} / \mathrm{h}$ (see also Figure $\mathrm{S} 1$ in the suplementary material). As expected, the three graphs show that turbidity decreases with increasing $\mathrm{L} / \mathrm{D}$ (from $\mathrm{L} / \mathrm{D}=14$ to $\mathrm{L} / \mathrm{D}=16$ ), as melting develops along the screw. Also, in all cases, PP is fully molten at $\mathrm{L} / \mathrm{D}=16$, that is, at the end of the second kneading block, before flow through the LH elements. One screw diameter earlier, that is, at $\mathrm{L} / \mathrm{D}=15$, just before entering the double set of kneading blocks, significant melting had already occurred at the lowest screw speed $(30 \mathrm{rpm})$, but the process tends to slow down with increasing screw speed. Consequently, most of the PP melting develops in the last screw turns of the conveying section upstream of the restrictive zone, which agrees well with previous experimental observations. ${ }^{[7,9]}$ Considering the "axial pressure profile" that can be anticipated from the analysis of Figure 4, it is most likely that from $\mathrm{L} / \mathrm{D}=13$ onward (depending on screw speed and extruder feed rate) the screw channels work fully filled, this triggering the higher melting rates.

When operating at the barrel set temperature of $175^{\circ} \mathrm{C}$ or above, PP is fully molten $1 \mathrm{~L} / \mathrm{D}$ upstream of the kneading blocks, that is, well inside the conveying section. This demonstrates that barrel temperature has an important contribution to melting due to radial heat conduction. While solid polymer particles and melt coexist, the higher the barrel temperature the lower the average turbidity values at the various sampling points. When the barrel is kept at $167^{\circ} \mathrm{C}$, turbidity values saturated at $\mathrm{L} / \mathrm{D}=14$ (and therefore are not shown in Figure 9A), given the higher content of solids. Generally, increasing the screw speeds have a tendency to hinder melting to some extent, as shown by the growing values of turbidity. As discussed above, at the low screw speed range residence times are higher, thus promoting heating by conduction, but shear rates are low and so the contribution of heat from friction and viscous dissipation is small. At high screw speeds, not only residence times are lower, so heat conduction becomes less important, but the role 

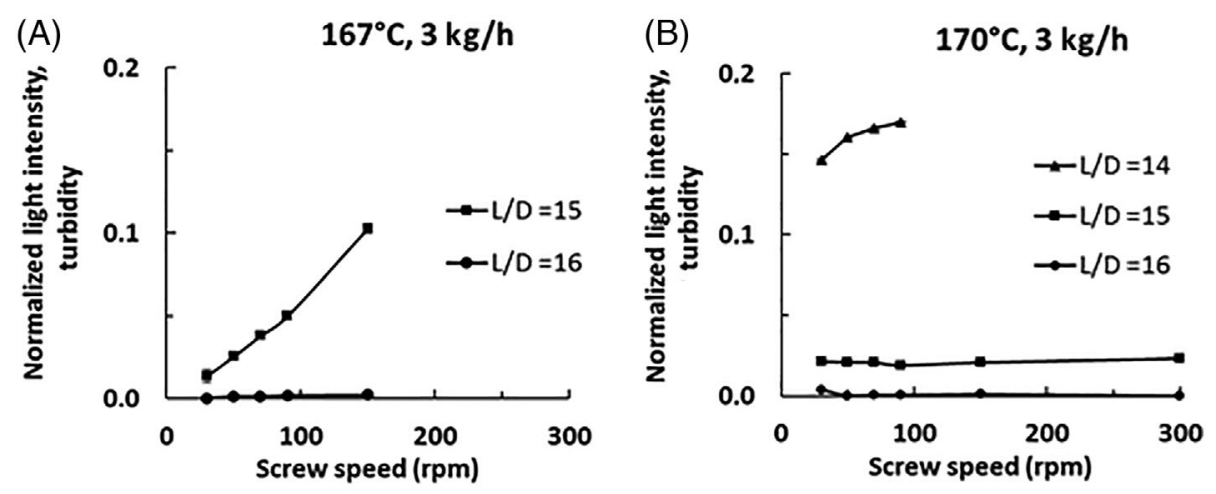

F I G URE 9 Effect of screw speed on turbidity, as normalized light intensity, at the different sampling locations $(\mathrm{L} / \mathrm{D}=14, \mathrm{~L} / \mathrm{D}=15$, and $\mathrm{L} / \mathrm{D}=16$ ), for three barrel temperatures (167, 170, and $175^{\circ} \mathrm{C}$, Figure $10 \mathrm{~A}, \mathrm{~B}$, and $\mathrm{C}$, respectively) for a fixed extruder feed rate of $3 \mathrm{~kg} / \mathrm{h}$. Error bars are smaller than the experimental symbols

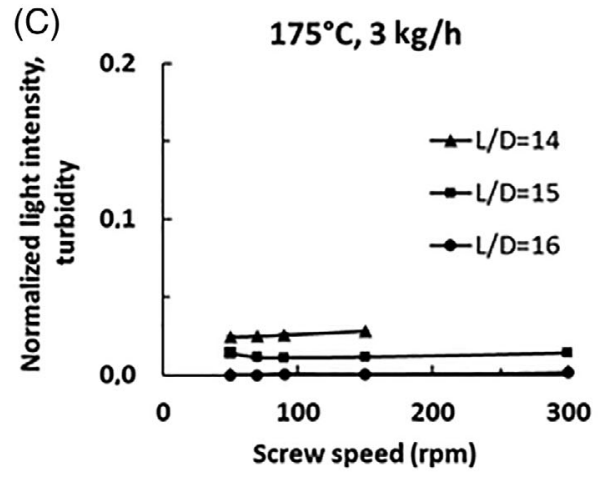

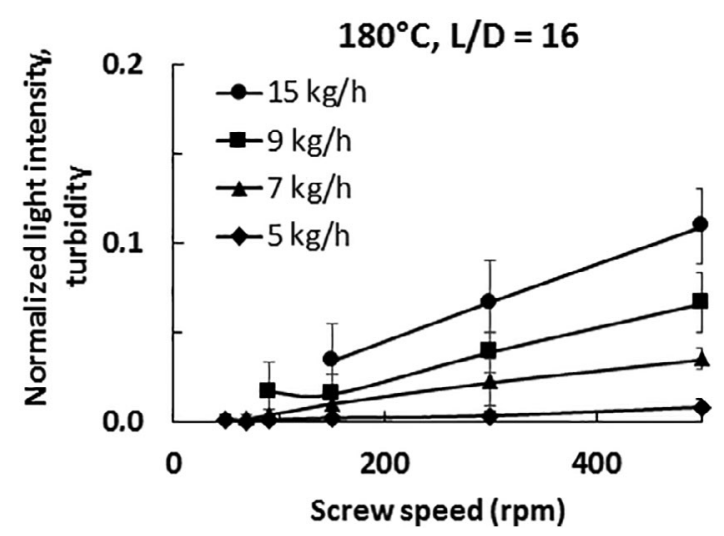

FI G U RE 10 Effect of extruder feed rate and screw speed on turbidity at $\mathrm{L} / \mathrm{D}=16$ and barrel temperature set at $180^{\circ} \mathrm{C}$. Error bars as shown

of viscous dissipation will not necessarily increase meaningfully due to the pseudoplastic behavior of molten PP.

Figure 10 shows the effect of extruder feed rate and screw speed on turbidity at $\mathrm{L} / \mathrm{D}=16$ for a barrel temperature of $180^{\circ} \mathrm{C}$. While in Figure 9, regardless of the barrel temperature, PP melting was completed at this location, it is now evident that increasing the extruder feed rate will systematically delay melting. Since higher extruder feed rate will induce lower residence times but higher viscous dissipation, the results seem to confirm that the former predominates over the latter for a polymer with a moderate MFI value such as the PP used in this study.
Online birefringence data can also estimate the content of molten polymer in a given screw channel location. In the solid state, the PP is partially crystallized. As there is no preferential orientation of the lamellas in the solid PP particles, they do not contribute to the OPD and so the cross-polarized transmitted light intensity measured online is not affected by the presence of solid particles. On the other hand, molten polymer chains will tend to orient in the flow direction, producing an OPD, the socalled flow birefringence. Just after melting in the extruder, the polymer is at a relatively low temperature, hence high viscosity levels are anticipated, which will induce strong molecular orientation in the flow direction. This orientation creates optical anisotropy, revealed as flow birefringence, which is quantified by the optical detector set with the pair of polarizers crossed. The inline flow birefringence of polystyrene with three different molecular weights have been measured during extrusion, using a rheo-polarimeter detector similar to the one used in this study. The birefringence values $(\Delta n)$ were lower than $-4 \times 10^{-4}$, the values increasing with molecular weight due to higher chain orientation. The value is negative because the polar benzene side group is set crossed to the main chain. The technique was validated using polycarbonate slabs with known and offline measured OPDs. ${ }^{[28]}$

Figure 11 shows the total birefringence as a function of screw speed (from 30 to $300 \mathrm{rpm}$ ) at different sampling locations ( $\mathrm{L} / \mathrm{D}=14, \mathrm{~L} / \mathrm{D}=15$, and $\mathrm{L} / \mathrm{D}=16)$, for two barrel temperatures $\left(170^{\circ} \mathrm{C}\right.$ and $\left.175^{\circ} \mathrm{C}\right)$ and a fixed 

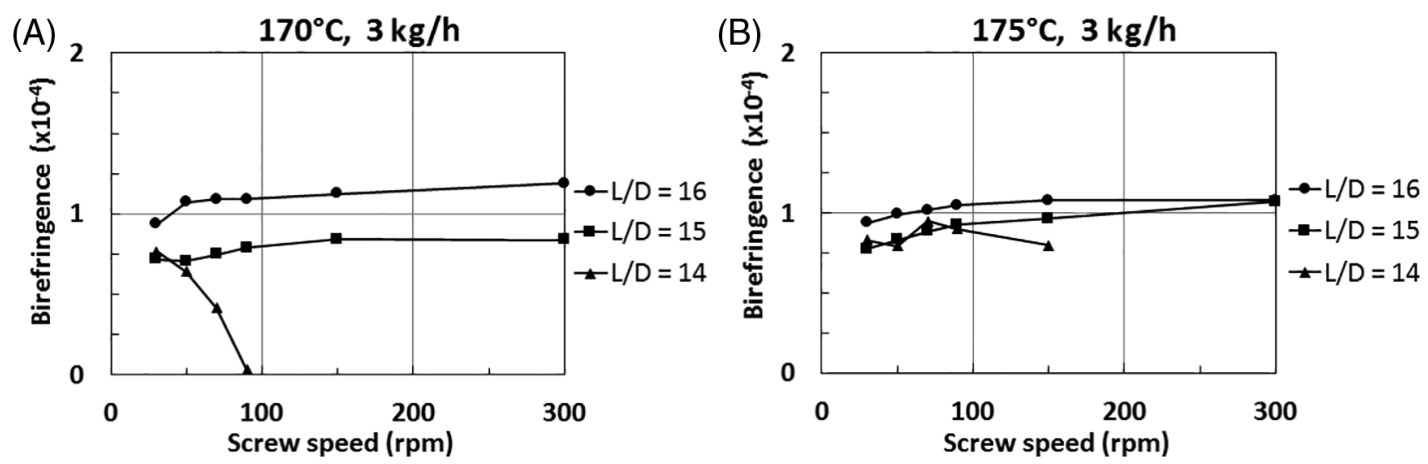

F I G U R E 11 Total birefringence as a function of screw speed (from 30 to $300 \mathrm{rpm}$ ) at different sampling locations (L/D = 14, L/D = 15, and $\mathrm{L} / \mathrm{D}=16)$, for two barrel temperatures $\left(170^{\circ} \mathrm{C}\right.$ and $175^{\circ} \mathrm{C}$, A and $\mathrm{B}$, respectively) and fixed extruder feed rate $(3 \mathrm{~kg} / \mathrm{h})$

FIG URE 12 Schematic representation of the axial melting profile of PP along the first restrictive zone of the screw, as measured by online optical monitoring, when operating at a constant extruder feed rate of $3 \mathrm{~kg} / \mathrm{h}$. The profiles are similar for a constant set barrel temperature of $170^{\circ} \mathrm{C}$ and varying screw speed, and a constant screw speed of $90 \mathrm{rpm}$ and varying barrel temperature, as indicated [Color figure can be viewed at wileyonlinelibrary.com]
PP melting profile @ $3 \mathbf{k g} / \mathbf{h}$

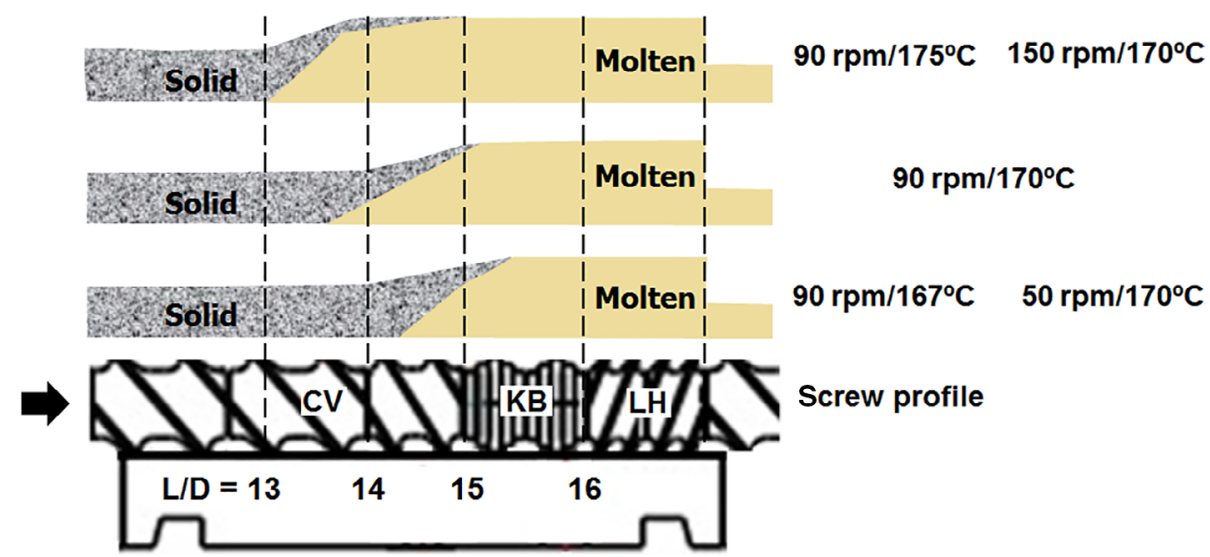

extruder feed rate of $3 \mathrm{~kg} / \mathrm{h}$ (see also Figure S2 in the suplementary material). When processing at $170^{\circ} \mathrm{C}$ and for all screw speeds, the polymer is fully molten before entering the kneading block at $\mathrm{L} / \mathrm{D}=15$, producing a flow birefringence of about $0.75 \times 10^{-4}$, which increases slightly at $\mathrm{L} / \mathrm{D}=16$ to approximately $1 \times 10^{-4}$. The values are low compared with PS due to the nonpolar character of the PP chain. The effect of screw speed can only be perceived for $\mathrm{L} / \mathrm{D}=14$, that is, for flow in the conveying section, and for the low screw speed range (below $90 \mathrm{rpm}$ ), as birefringence becomes nil for higher speeds. At this location and for low screw speeds, the flow of material comprises molten polymer and solid PP particles. As the screw speed increases until $90 \mathrm{rpm}$, the degree of fill of the channel will decrease, and birefringence will reduce progressively. As discussed, at higher screw speeds melting will be delayed, hence the flow of mostly solid particles will not contribute to the flow birefringence. These effects were identified when measuring turbidity, as shown in Figure 9B. At higher barrel temperature $\left(175^{\circ} \mathrm{C}\right)$, the birefringence levels off to a value of approximately $1 \times 10^{-4}$, independently of screw position and speed. As shown in Figure 7, the polymer takes approximately 4 seconds $\left(\Delta t=\left(t_{m}^{L / D=16}=52 \mathrm{~s}\right)\right.$ $\left.-\left(t_{m}^{L / D=15}=48 \mathrm{~s}\right)\right)$ to flow from $\mathrm{L} / \mathrm{D}=15$ to 16 when the screws rotate at $50 \mathrm{rpm}$, the value reducing to 3 seconds (21 to 19 seconds) for a speed of $300 \mathrm{rpm}$. Since these times are long enough to relax the molecular orientation induced by the screws rotation, the birefringence measured results merely from the contribution of the molecular orientation of the molten stream fraction, induced upon flow along the slit die.

\subsection{Axial melting profile}

From the optical online measurements reported and discussed throughout this section, it is possible to build the axial melting profile of PP at $90 \mathrm{rpm}$ and barrel temperatures starting from just above its theoretical melting temperature (taken as $165^{\circ} \mathrm{C}$ ) up to $175^{\circ} \mathrm{C}$. The same profiles are obtained when the set barrel temperature is fixed at 
$170^{\circ} \mathrm{C}$ and the screw speeds vary from 50 to $150 \mathrm{rpm}$, as shown in Figure 12, for the screw geometry shown in Figure 2 . The figure represents schematically the evolution of the relative amount of solid particles and molten material along the initial part of the screw (ie, no claim of the existence of a solid bed and a contiguous melt pool is being made based on the optical measurements performed). The figure identifies also whether the channels work fully or partially filled by considering the data for the slit flow rate in each slit. An increase of either $100 \mathrm{rpm}$ in the screw speed or just $8^{\circ} \mathrm{C}$ in the set barrel temperature can shift meaningfully the melting profile in the upstream direction. Within the operating window explored in this study (50 to $150 \mathrm{rpm}$ and $167^{\circ} \mathrm{C}$ to $175^{\circ} \mathrm{C}$ ), the solids move forward in partially filled channels that become progressively filled due to the flow resistance created by the restrictive LH elements downstream. The onset of melting seems to take place in partially filled conveying elements; melting develops quickly as the latter become fully filled, and is completed well before flow through the kneading blocks.

\section{4 | CONCLUSIONS}

An experimental setup containing a modified barrel module and a sliding online optical device was successfully used to monitor in real-time the melting progress of a polypropylene in the first screw restrictive zone of a corotating intermeshing twin-screw extruder. While operating under steady state conditions, part of the flow was diverted out of the main stream at specific L/D locations along the extruder. The PP molten fraction in the flow was estimated by measuring its turbidity and flow birefringence. Turbidity, that is, light scattering as transmitted light intensity, declined as melting developed, since the content of solidmolten polymer interfaces decreased. Conversely, birefringence increased as melting progressed, as the content of oriented polymer chains in the molten phase increases.

Axial melting profiles were built from the online optical data. At a constant extruder feed rate of $3 \mathrm{~kg} / \mathrm{h}$, similar melting profiles were obtained for the screws rotating at $90 \mathrm{rpm}$ and barrel temperatures set between $167^{\circ} \mathrm{C}$ and $175^{\circ} \mathrm{C}$, and for a barrel temperature set at $170^{\circ} \mathrm{C}$ and screw speeds varying from 50 up to $150 \mathrm{rpm}$. An increase of $100 \mathrm{rpm}$ in screw speed or of $8^{\circ} \mathrm{C}$ in the set barrel temperature can shift meaningfully the melting profile in the upstream direction.

Generally, the onset of melting took place in partially filled conveying elements upstream of the first restrictive zone. As the channels become fully filled melting progresses quickly, the process being completed well before flow through the $90^{\circ}$ kneading block.

\section{ACKNOWLEDGMENTS}

This study was financed in part by the Coordenação de Aperfeiçoamento de Pessoal de Nível Superior-Brasil (CAPES)—Finance Code 001, PDSE 88881.132167/201601 scholarship to L.A. Bicalho, grant PVE 30484/2013-01 to J.A. Covas and Conselho Nacional de Desenvolvimento Científico e Tecnológico (CNPq) for a PQ scholarship 311790/2013-5 to S.V. Canevarolo, and the Programa de Pós-Graduação em Ciência e Engenharia de Materiais (PPG-CEM) of UFSCar. The assistance of the technicians from DEMa/UFSCar and IPC/UMINHO is also gratefully acknowledged.

\section{ORCID}

Sebastião Vicente Canevarolo (D) https://orcid.org/00000002-7959-1872

\section{REFERENCES}

[1] K. Kohlgrüber, Co-Rotating Twin-Screw Extruder, Carl Hanser Verlag, Munich 2012.

[2] Z. Tadmor, C. G. Gogos, Principles of Polymer Processing, 2, John Wiley \& Sons, USA 2006.

[3] P. Andersen. Fundamentals of twin-screw extrusion polymer melting: Common pitfalls and how to avoid them. Paper presented at: AIP Conference Proceedings, 2015, 1664, 020007. https://doi.org/10.1063/1.4918387.

[4] A. V. Machado, J. A. Covas, M. Walet, M. Van Duin, J Appl Polym Sci 2001, 80(9), 1535. http://dx.doi.org/10.1002/app.1245.

[5] P. Rodrigues, R. M. Santos, M. C. Paiva, J. A. Covas, Int Polym Process 2017, 32(5), 614. http://dx.doi.org/10.3139/217.3485.

[6] C. E. Scott, C. W. Macosko, Polym bull 1991, 26(3), 341. http:// dx.doi.org/10.1007/bf00587979.

[7] B. Vergnes, G. Souveton, M. L. Delacour, A. Ainser, Int Polym Process 2001, 16(4), 351. http://dx.doi.org/10.3139/217.1662.

[8] H. Chen, U. Sundararaj, K. Nandakumar, M. D. Wetzel, Ind Eng Chem Res 2004, 43(21), 6822. http://dx.doi.org/10.1021/ ie049650s.

[9] A. Vera Machado, V. Yquel, J. A. Covas, J-J. Flat, N. Ghamri, A. Wollny, Macromolecular Symposia 2006, 233(1), 86. http:// dx.doi.org/10.1002/masy.200690032.

[10] C. Teixeira, A. Gaspar-Cunha, J. A. Covas, Polym-Plast Technol Eng 2012, 51(15), 1567. http://dx.doi.org/10.1080/ 03602559.2012 .716477$.

[11] C. C. Gogos, C. C. Tadmor, M. H. Kim, Advances in Polymer Technology 1998, 17(4), 285. http://dx.doi.org/10.1002/(sici) 1098-2329(199824)17:4<285::aid-adv1>3.0.co;2-n

[12] B. Maddock, SPE J 1959, 15, 383.

[13] A. V. Machado, J. A. Covas, M. Van Duin, J Appl Polym Sci 1999, 71(1), 135. http://dx.doi.org/10.1002/(sici)1097-4628 (19990103)71:1<135::aid-app16>3.0.co;2-m.

[14] The Japan Steel Works L. Visualization Method for Analysis of Polymer Behavior in TEX. [Tech information], 2017, http:// www.jsw.de/jsw/wp-content/uploads/2017/12/Visual.pdf [Accessed May 16, 2019].

[15] H. Chen, U. Sundararaj, K. Nandakumar, M. D. Wetzel, Int Polym Process 2004, 19(4), 342. http://dx.doi.org/10.3139/217. 1839. 
[16] F. Apruzzese, J. Pato, S. T. Balke, L. L. Diosady, Food Res Int 2003, 36(5), 461. http://dx.doi.org/10.1016/s0963-9969(02)00193-x.

[17] F. O. C. Bernardo, J. M. Silva, S. V. Canevarolo, Polym Test 2018, 70, 449. http://dx.doi.org/10.1016/j.polymertesting.2018.08.005.

[18] L. A. Bicalho, J. M. J. da Silva, J. A. Covas, S. V. Canevarolo, J Therm Anal Calorim 2017, 130, 2093. http://dx.doi.org/10. 1007/s10973-017-6714-5.

[19] J. A. Covas, J. M. Nóbrega, J. M. Maia, Polym Test 2000, 19(6), 725. http://dx.doi.org/10.1016/s0142-9418(00)00025-8.

[20] T. M. Gasparini, S. V. Canevarolo, Polym Test 2019, 80, 106126. http://dx.doi.org/10.1016/j.polymertesting.2019.106126.

[21] L. H. B. Johansen, L. B. Canto, S. V. Canevarolo, Int Polym Process 2016, 31(5), 607. http://dx.doi.org/10.3139/217.3241.

[22] F. Legrand, J. Piau, J Non-Newtonian Fluid Mech 1998, 77(1-2), 123. http://dx.doi.org/10.1016/s0377-0257(97)00129-8.

[23] T. J. A. Mélo, S. V. Canevarolo, Polym Eng Sci 2002, 42(1), 170. http://dx.doi.org/10.1002/pen.10938.

[24] A. Poulesquen, B. Vergnes, P. Cassagnau, A. Michel, O. S. Carneiro, J. A. Covas, Polym Eng Sci 2003, 43(12), 1849. http:// dx.doi.org/10.1002/pen.10157.

[25] K. C. Reis, S. V. Canevarolo, Polym Eng Sci 2012, 52(8), 1784. http://dx.doi.org/10.1002/pen.23129.

[26] J. Silva, S. V. Canevarolo, J Appl Polym Sci 2016, 133, 44066. http://dx.doi.org/10.1002/app.44066.

[27] J. Silva, A. C. Santos, S. V. Canevarolo, Polym Test 2015, 41, 63. http://dx.doi.org/10.1016/j.polymertesting.2014.10.007.
[28] K. Soares, A. M. da Cunha Santos, S. V. Canevarolo, Polym Test 2011, 30(8), 848. http://dx.doi.org/10.1016/j.polymertesting.2011. 08.007 .

[29] L. Zborowski, S. V. Canevarolo, Polym Test 2012, 31(2), 254. http://dx.doi.org/10.1016/j.polymertesting.2011.11.004.

[30] L. Zborowski, S. V. Canevarolo, Polym Eng Sci 2013, 53(11), 2422. http://dx.doi.org/10.1002/pen.23490.

[31] X. Zhang, Z-B. Xu, L-F. Feng, X-B. Song, G-H Hu, Polym Eng Sci 2006, 46(4), 510. http://dx.doi.org/10.1002/pen.20495.

[32] International Light Technologies I, 2019, https://www.intllighttech.com/product-group/light-meters [Accessed May 16, 2019].

\section{SUPPORTING INFORMATION}

Additional supporting information may be found online in the Supporting Information section at the end of this article.

How to cite this article: Bicalho LA, Covas JA, Canevarolo SV. Online optical monitoring of polymer melting in a twin-screw extruder. Polym Eng Sci. 2020;60:2163-2175. https://doi.org/10. 1002/pen.25460 